\title{
AiMT
}

Advances in Military Technology

Vol. 15, No. 2, 2020, pp. 465-475

ISSN 1802-2308, eISSN 2533-4123

DOI 10.3849/aimt.01401

\section{Reduction of Corrosion Rate of Aluminium Alloy 6061 through Anodization}

\author{
M.F.A. Samad* and R. Ramle \\ Faculty of Mechanical Engineering, Universiti Teknikal Malaysia Melaka, Malaysia
}

The manuscript was received on 23 March 2020 and was accepted after revision for publication as research paper on 20 November 2020 .

\begin{abstract}
:
This paper focuses on reducing the corrosion rate of aluminium alloy 6061 through anodizing. The study involves characterizing corrosion phenomenon that occurs on aluminium alloy 6061 in relation to parameters involved in an anodizing process, in particular the current density of anodizing, and its corrosion environment; specifically, the concentration and $\mathrm{pH}$ value of the corrosion accelerator. The experiment samples were anodized in sulphuric acid $\left(\mathrm{H}_{2} \mathrm{SO}_{4}\right)$ at a current density ranging from $0.012 \mathrm{~A} / \mathrm{mm}^{2}$ to $0.018 \mathrm{~A} / \mathrm{mm}^{2}$. The paper also includes a qualitative analysis of corrosion images obtained from the experiment through scanning electron microscope. It concludes that corrosion rate may be reduced through an increase of current density during anodizing.
\end{abstract}

\section{Keywords:}

aluminium alloy, anodizing, corrosion, electrochemical process

\section{Introduction}

Since the 1920s, steel had been the dominant material used in building automobiles. Shortly after that, aluminium alloy emerged as the best material applied in automotive industries for structural application. It is also known as the second best material, second only to steel, in metal industry. The preference has been based on characteristics such as light mass, non-rusting properties, reasonably good strength, easy fabrication and favourable economics, coupled with modern metallurgical control of structure and properties. Today, aluminium alloy comes with a wide range of properties and it is often used in engineering structures.

The properties of aluminium alloy that include high stiffness strength to mass ratio, good formability and recycling potential make it the ideal candidate to replace

\footnotetext{
* Corresponding author: Faculty of Mechanical Engineering, Universiti Teknikal Malaysia Melaka, Hang Tuah Jaya, MY-76100 Durian Tunggal, Melaka, Malaysia. Phone: +(60)6 27043 57, Fax: +(60)6 270 10 46, E-mail:mdfahmi@utem.edu.my
} 
heavier materials (steel or copper) to respond to the mass reduction demand in the automotive industry [1].

The use of aluminium at the expense of steel has been on a part-by-part basis, not the result of any radical design change. Most of the aluminium applications have been in transmissions, engine blocks, and wheels, largely as castings with some forgings and extrusions. Despite the high cost, in the past three decades, the amount of aluminium in automobiles has increased steadily. However, like any other metal material, aluminium alloy suffers some disadvantages. These include its tendency to serrated yielding during stretching and drawing, loss of strength during annealing of paint bake cycle, and corrosion $[2,3]$.

In [4], on a research of corrosion resistance of aluminium alloy for the automotive industry, it was found that the corrosion resistance is created by a combination of two features. First, during brazing, silicon ( $\mathrm{Si}$ ) was diffused into the core. In the diffusion zone, small particles of Al-Mn-Si precipitate adjacent to the core or clad interface with a width of around $20-50 \mu \mathrm{m}$. It mentioned that, in order to have a good, overall formability, the materials should have an isotropic mechanical property. In sheet product of 6000 alloys, it is always the case that the end material has a relatively strong recrystallization texture. A study verified that aluminium alloy has far greater corrosion resistance than steel, as found through simulated marine and industrial environment [5]. Meanwhile, a study in [6] was done on corrosion protection properties of anodic oxide coatings on an Al-Si alloy. Oxide coatings were successfully deposited on a cast Al-Si alloy by hard anodizing, modified anodizing and other anodizing techniques. Researchers observed small cracks and pores near second-phase particles caused by internal stress as a result of the different film growth rates for the different anodizing phases. A study in [7] emphasized the significance of current density in anodizing process. It improved the characteristics of metal in various terms, namely charging ability and capacitance.

This paper provides an extension to the study of corrosion protection of aluminium alloy, by directly relating an observed corrosion phenomenon to the parameters of anodizing. The study involves the process of anodizing and corrosion testing. In the study, corrosion is tested through salt spray test and observed from a variety of aspects - mass loss, corrosion rate and microstructural observation. The study also investigates the effect of anodizing from the perspective of several independent settings current density in the anodizing process, molar concentration of the corrosion accelerator and $\mathrm{pH}$ value of the corrosion accelerator. Other sections are as follows: Section 2 explains the setup and how the experimental investigation was performed. Section 3 provides the results and discussion based on the aspects mentioned earlier including photographs of microstructure corrosion. The last section concludes the finding.

\section{Methodology}

\subsection{Design of Experiment}

The investigation of corrosion rate was carried out based on American Standard of Testing and Material i.e. ASTM G 46-94 (Reapproved 1999) which provide assistance in the selection of procedure for the identification and examination of pits, evaluation of pitting corrosion and determination of the extent of pitting corrosion effect [8]. 
The raw materials are Aluminium Alloy 6061-T4 sheets. The chemical composition of the material is provided in Tab. 1 [9]. For the anodizing process, the complete list of equipment is as follows:

- beakers,

- power supply 0-100 volt,

- crocodile clips,

- sulphuric acid $\left(\mathrm{H}_{2} \mathrm{SO}_{4}\right)$,

- test samples (Al-6061).

For acceleration of corrosion, the chemical used is diluted sodium chloride $(\mathrm{NaCl})$, also known as salt. This chemical is known to be able to accelerate corrosion, more familiarly in a salt spray test. To remove any trace of corrosion before corrosion acceleration start, the samples were cleaned using sand paper and water. A digital thermometer and a $\mathrm{pH}$ meter were also used to record the temperature and the $\mathrm{pH}$ level of the $\mathrm{NaCl}$ solution (in the immersion phase) from time to time in ensuring a constant condition. Other materials are explained in respective sections. The complete flow of the laboratory work may be represented as in Fig. 1.

Tab. 1 Chemical composition of Aluminium Alloy 6061-T4

\begin{tabular}{|c|c||c|c|}
\hline Component & Mass [\%] & Component & Mass [\%] \\
\hline \hline Silicon & $0.40-0.8$ & Chromium & $0.04-0.35$ \\
\hline Iron & 0.7 & Zinc & 0.25 \\
\hline Copper & $0.15-0.40$ & Titanium & 0.15 \\
\hline Manganese & 0.15 & Aluminium & Remainder \\
\hline Magnesium & $0.8-1.2$ & Others & $0.15(0.05$ each $)$ \\
\hline
\end{tabular}

\subsection{Test Sample Preparation}

The material was cut into $30 \mathrm{~mm}$ long and $1.695 \mathrm{~mm}$ thick test samples. The samples to be set as the cathode in the anodization were $10 \mathrm{~mm}$ wide whereas the anode was $30 \mathrm{~mm}$ wide. The test samples were cut into specific size to ease handling and observation under microscope. Both types were prepared in 15 samples, where each set was divided into uncoated (which experience no anodizing) and coated (with different current density setting). Furthermore, these sets were later divided into accelerated corrosion in different concentration (molarity) of $\mathrm{NaCl}$.

\subsection{Anodizing Process}

Each of the samples was placed in designated beaker containing $\mathrm{H}_{2} \mathrm{SO}_{4}$ according to whether current was applied or not. Several runs were made at which different current densities were set for the samples, before these samples were placed into different $\mathrm{Na}$ $\mathrm{Cl}$ concentration. The current density reading for each of the samples was taken from time to time. This was to ensure that the density current for each of the samples were constant. This was observed for 20-30 min of the process, maintained at $0.012 \mathrm{~A} / \mathrm{mm}^{2}$ and $0.018 \mathrm{~A} / \mathrm{mm}^{2}$.

In the meantime, the temperature in the anodizing electrolyte was controlled. The temperature control was within $\pm 1{ }^{\circ} \mathrm{C}$ or even $\pm 0.5{ }^{\circ} \mathrm{C}$. The minimum separation distance of $25 \mathrm{~cm}$ was kept between the cathode and anode. To note, the results of the anodizing process were referred to as the coated samples, while some samples were kept uncoated. 


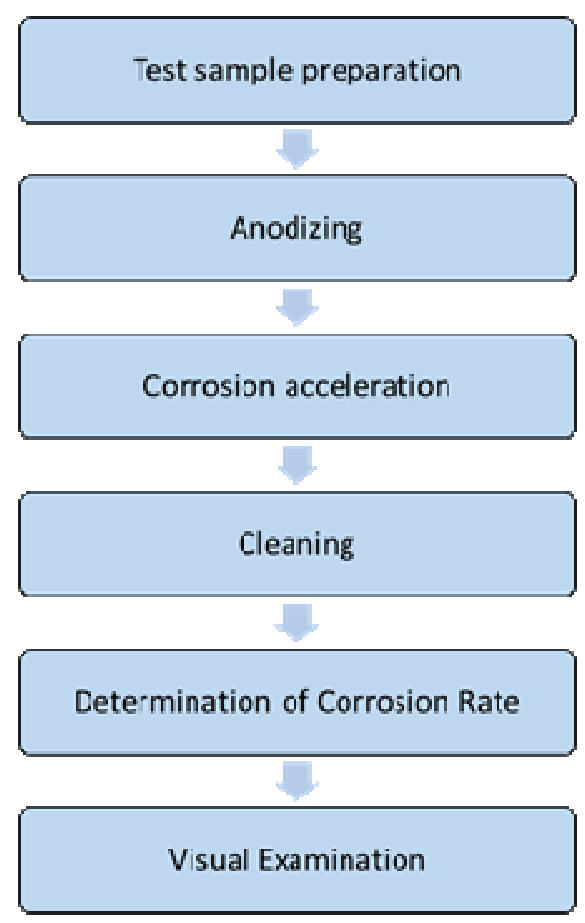

Fig. 1 Research steps

\subsection{Corrosion Acceleration}

After anodizing, the samples were taken for mass measurement. The average mass of the samples to be immersed into sodium chloride $(\mathrm{NaCl})$ was $0.9779 \mathrm{~g}$. The samples were then immersed into different concentrations of $\mathrm{NaCl}$ to determine the effect of salt solution concentration on the rate of pitting corrosion. The molecular weight of $\mathrm{NaCl}$ was $58.44 \mathrm{~g} / \mathrm{mol}$. The weight of $\mathrm{NaCl}$ needed in the preparation of 5 different concentrations of diluted $\mathrm{NaCl}$ was calculated as follows in Tab. 2.

Tab. 2 Weight of $\mathrm{NaCl}$ for different concentration of $\mathrm{NaCl}$ solution

\begin{tabular}{|c|c|}
\hline NaCl concentration [molar] & Weight [gram] \\
\hline \hline 0.5 & 1.46 \\
\hline 1.0 & 2.92 \\
\hline 1.5 & 4.38 \\
\hline 2.0 & 5.84 \\
\hline 2.5 & 7.31 \\
\hline
\end{tabular}

For a $0.5 \mathrm{M} \mathrm{NaCl}$ of $50 \mathrm{ml}$ solution, weight $=58.44 \mathrm{~g} / \mathrm{mol} \times 0.5 \mathrm{~mol} / \mathrm{l} \times 0.05 \mathrm{l}=$ $1.46 \mathrm{~g}$.

Each sample was left exposed to the atmosphere for a period of 35 days ( 840 hours) before being analysed for corrosion. The temperature and humidity of the test environment were checked periodically for any sudden change. 


\subsection{Cleaning}

In determining the mass loss for corrosion rate, the samples must first be cleaned. ASTM G 1-90 (Reapproved 1999) was used as a reference guide [10]. The surfaces of the corroded part were cleaned by using sand paper grade 250 followed by sand paper grade 1250 (as a polishing guide). When there were still traces of corroded film, the steps mentioned above were repeated until satisfactory result was reached.

A solution of $50 \mathrm{ml}$ phosphoric acid and $20 \mathrm{~g}$ chromium trioxide was prepared to clean the corrosion film. The solution was boiled to about $90{ }^{\circ} \mathrm{C}$ for about $5 \mathrm{~min}$ to 10 min. By using a brush, the samples were lightly brushed using the cleaning solution followed by a light brushing in $1000 \mathrm{ml}$ of reagent water. If corroded film still appeared, another light brushing using cleaning solution and reagent water was repeated until no sign of corroded film appear.

The samples were then rinsed with nitric acid. The solution of nitric acid was prepared by boiling it from $20^{\circ} \mathrm{C}$ to $25{ }^{\circ} \mathrm{C}$ of temperature for about $1 \mathrm{~min}$ to $5 \mathrm{~min}$. Then the samples were rinsed thoroughly with water and immediately dried at room temperature. For mass loss determination, a lab grade weighing scale was used.

\subsection{Determination of Corrosion Rate}

In determining the corrosion rate, the following assumptions were made:

- the use of corrosion rate implies that all mass loss had been due to general corrosion such as pitting, knife line etc.,

- the use of corrosion rate implies that the sample had not been internally attacked such as by dezincification or intergranular corrosion.

Assuming internal corrosion did not happen, the average corrosion rate may then be obtained as follows:

$$
\text { Corrosion rate }=\frac{K W}{A T D}
$$

where $K$ is the constant depending on the corrosion unit expression which is $8.76 \times 10^{4}$ for corrosion rate in mm/year, $T$ is the time of exposure in hours, $A$ is the area in $\mathrm{cm}^{2}$, $W$ is the mass loss in $\mathrm{g}$ and $D$ is the density in $\mathrm{g} / \mathrm{cm}^{3}$.

\subsection{Examination}

The procedure to examine pitting corrosion in this project was referred from ASTM G 46-94 (Reapproved 1999) standard [8]. By visual inspection, the extent of corrosion and the apparent location of pitting corrosion were determined under normal light. Detailed examination was also done by using an optical microscope and Scanning Electron Microscope.

\section{Results and Discussion}

\subsection{Mass Loss Data Analysis}

The mass loss data was collected by the difference in the weight of the samples before immersion into $\mathrm{NaCl}$ solution and after cleaning of the samples (also after the process of anodization and corrosion). Fig. 2 shows the mass loss of samples against different molarity of $\mathrm{NaCl}$ solution (acting as the electrolyte) and against different level of electrical current density during anodization. 


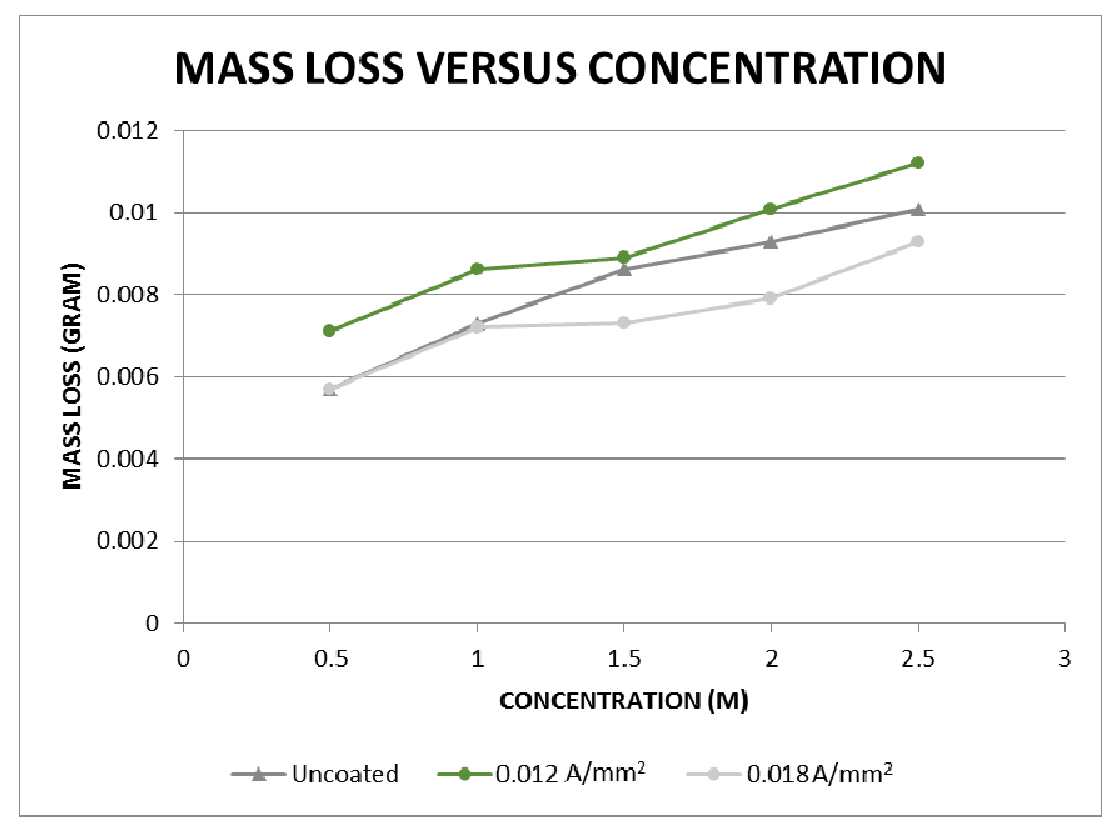

Fig. 2 Mass loss vs $\mathrm{NaCl}$ concentration

It shows that the mass loss of the samples that were immersed in different concentration have an overall ascending trend line. This shows that concentration (or molarity) of solution is one of the factors that contribute to the corrosion of the samples. The graph also shows that by using higher level of current density for the samples, the mass loss value is decreased.

The mass loss is calculated when pitting corrosion appears; it is most commonly produced by halide ions of which chloride is the most frequently encountered in testing. Pitting of aluminium in halide solution open to air occurs because, in the presence of oxygen, the metal is readily polarized to its pitting potential.

Nonetheless, metal mass loss is not ordinarily recommended for use as a measure of the extent (depth) of pitting unless general corrosion is slight and the pitting is fairly severe. If uniform corrosion is significant, the contribution of pitting to total metal loss is small, and pitting damage cannot be determined accurately from mass loss. In any case, mass loss can provide information about total metal loss due to pitting, but nothing about the depth of penetration. However, mass loss should not be neglected in every case because it may be of value; for example, mass loss along with a visual comparison of pitted surfaces may be adequate to evaluate the pitting resistance of alloys in laboratory tests.

\subsection{Rate of Corrosion}

The rate of corrosion was determined and presented as in Fig. 3. It shows that the rates of corrosion increase as the concentration of $\mathrm{NaCl}$ increases. From this study, it is also seen that the level of current density has an effect on the rate of corrosion of the sample, too. It is found that with higher current density, the corrosion rate decreases. This may be due to high growth rate of oxide when using high current density [11]. The solution concentration and also the anodizing process characterize the electrochemical 
nature of the corrosion process. These factors are of considerable importance when evaluating corrosion resistance. Time is not a factor in determining the rate of corrosion because corrosion rates are not necessarily constant with time of exposure. Some metals corrode within $24 \mathrm{~h}$ of exposure without prevention and some other take days, even months, for the metal to corrode.

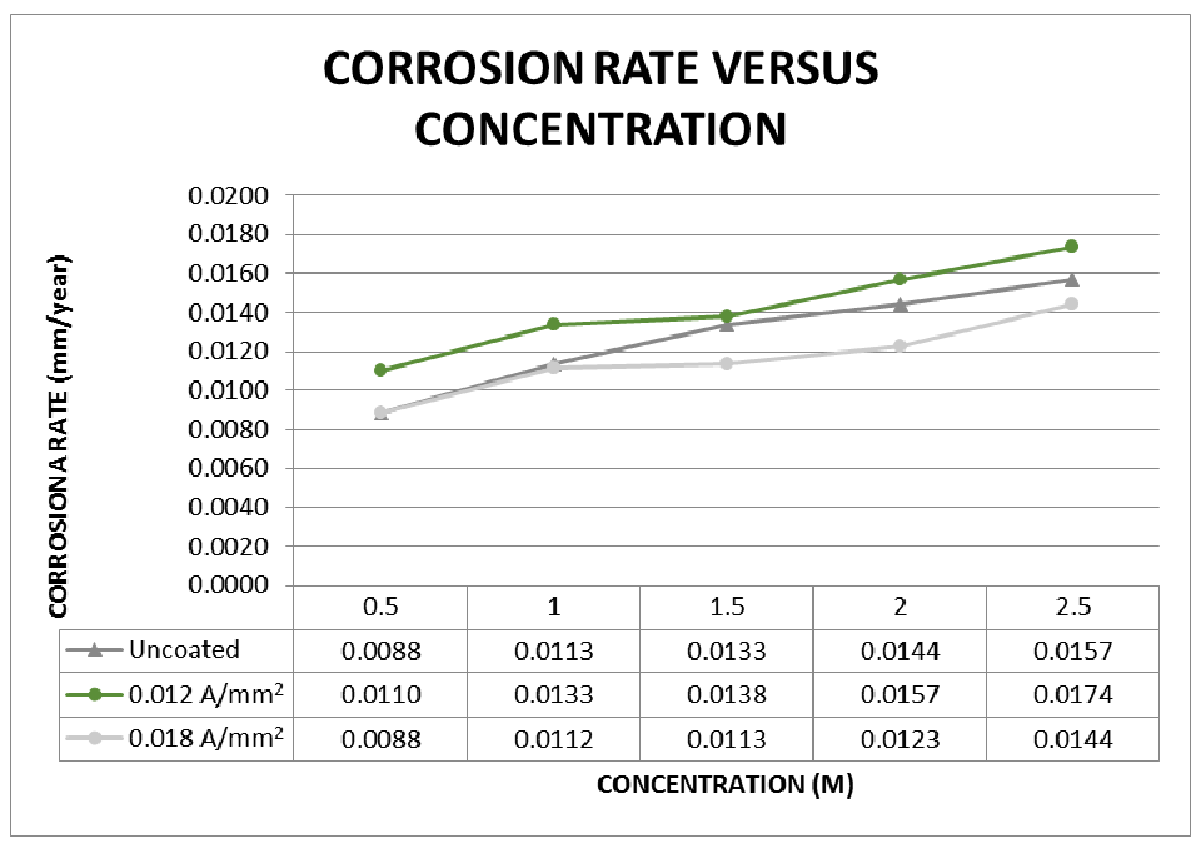

Fig. 3 Corrosion rate vs $\mathrm{NaCl}$ concentration

The following part studies the relationship between the corrosion rate and $\mathrm{pH}$ value of solution. Provided in Tab. 3 are the $\mathrm{pH}$ values for the sodium chloride solution of different concentration. Fig. 4 shows the corrosion rate versus $\mathrm{pH}$ value of the solution concentration. The figure shows that there is a nonlinear descending relationship between the corrosion rate and $\mathrm{pH}$ value of the solution. The condition for the thermodynamic stability of the oxide films, as expressed in Pourbaix diagram, stated that aluminium alloy is passive in the $\mathrm{pH}$ range of 4 to 8.5 . Beyond the limits of its passive range, aluminium corrodes in aqueous solution because their oxides are soluble in many acids and bases, yielding $\mathrm{Al}^{3}$ ions in the former and $\mathrm{AlO}_{2}$ ions in the latter [12]. There are, however, instances when corrosion does not occur outside the passive range, for example, when the oxide film is not soluble or when the film is maintained by the oxidizing nature of the solution.

Tab. $3 \mathrm{pH}$ value for different concentration of sodium chloride solution

\begin{tabular}{|c|c|}
\hline Concentration & pH Value \\
\hline $0.5 \mathrm{M}$ & 5.90 \\
\hline $1.0 \mathrm{M}$ & 5.65 \\
\hline $1.5 \mathrm{M}$ & 5.51 \\
\hline $2.0 \mathrm{M}$ & 5.48 \\
\hline $2.5 \mathrm{M}$ & 5.40 \\
\hline
\end{tabular}




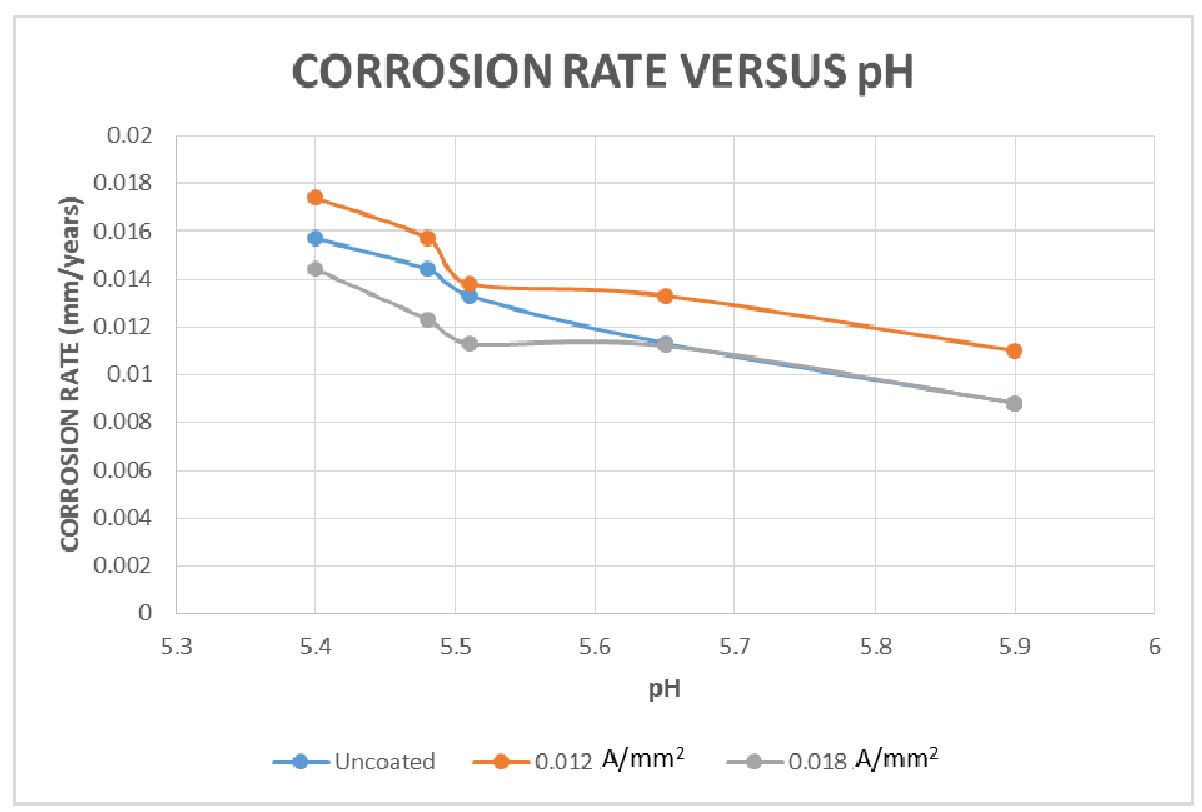

Fig. 4 Corrosion rate vs pH value of $\mathrm{NaCl}$

\subsection{Visual Observation}

Figs 5-7 show the visual images of corrosion which occurred on the samples collected using scanning electron microscope. This procedure is part of proving that there is pitting corrosion beneath the apparently smooth surface.

The figures show the location at which corrosion started to attack (see in particular Fig. 5b). During the period of salt spray test until 840 h or 35 days of exposure, the corrosion only appears at the surface.

From the figures, it appears that the oxide barriers of aluminium alloy that act as a coating on the surface for around $1 \mathrm{~nm}$ thickness had been destroyed, thus the pitting starts to attack and gaining depth in the sample. Some parts of the SEM images show that the coating started to tear apart and degrade. This happened because the sulphuric acid had started to combine with sodium hydroxide $(\mathrm{NaOH})$ and acted as a solution or medium of transfer for the ions of aluminium to attack the oxide barriers of aluminium alloy.

The first detected corrosion is pitting corrosion. It ordinarily penetrates from the top of a horizontal surface downwards in a nearly vertical direction. It is an extremely insidious type of corrosion, often going undetected and with very little material loss until failure occurs. The mechanism of pitting corrosion very much resembles crevice corrosion in which oxidation occurs within the pits itself with complementary reduction on its surface. Mostly, it occurs under the influence of gravity where it causes the pit to grow downward as the solution at the pit tip becomes more concentrated and dense. 


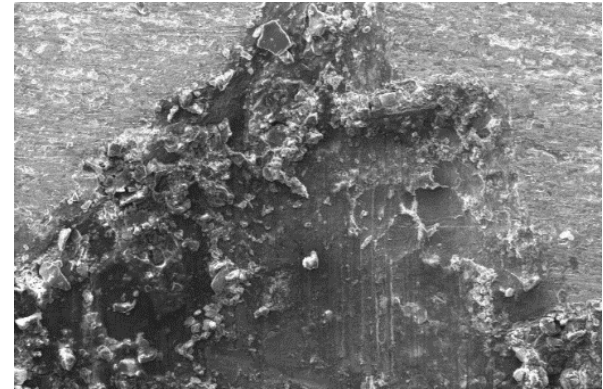

a)

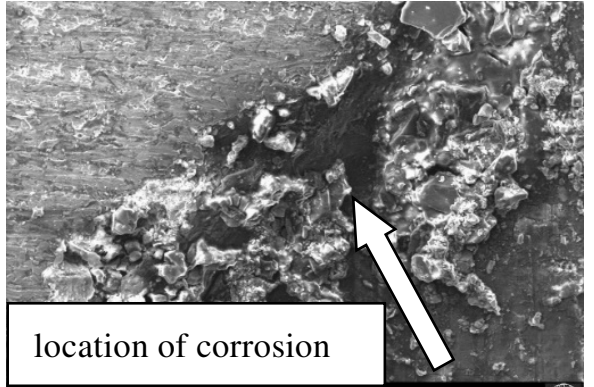

b)

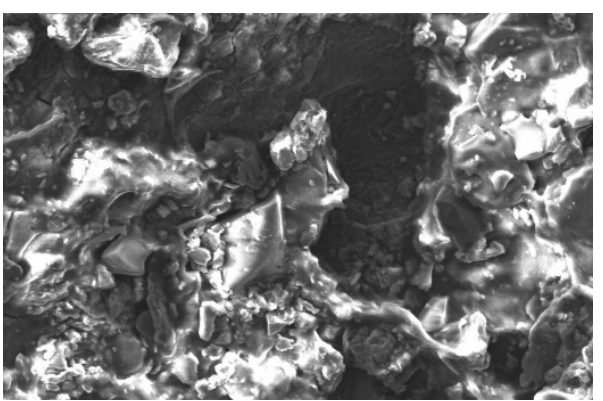

c)

Fig. 5 SEM Image for uncoated sample under magnification $1000 X$ in (a) $0.5 \mathrm{M}$ (b) $1.0 \mathrm{M}$ and (c) $1.5 \mathrm{M} \mathrm{NaCl}$ solution

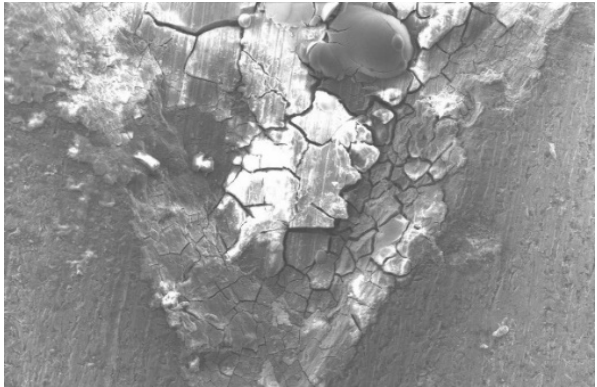

a)

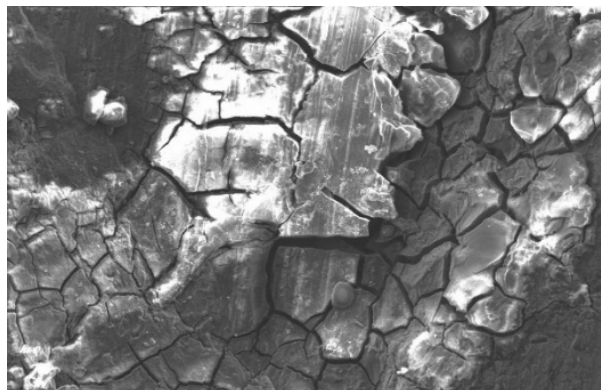

b)

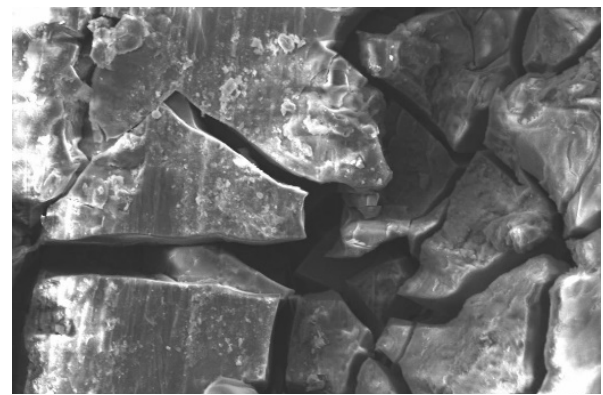

c)

Fig. 6 SEM Image for coated sample of $0.012 \mathrm{~A} / \mathrm{mm}^{2}$ current density under magnification $1000 \mathrm{X}$ in (a) $0.5 \mathrm{M}(b) 1.0 \mathrm{M}$ and (c) $1.5 \mathrm{M} \mathrm{NaCl}$ solution 


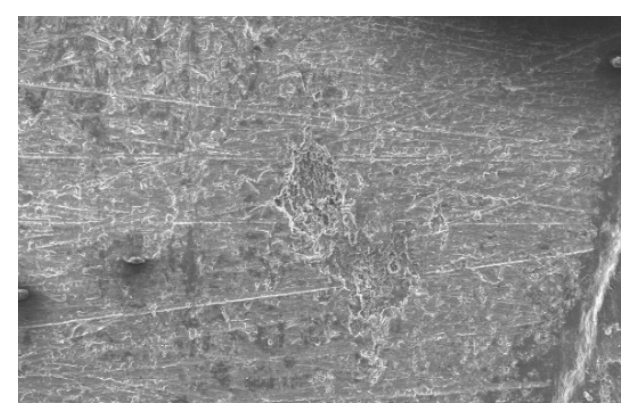

(a)

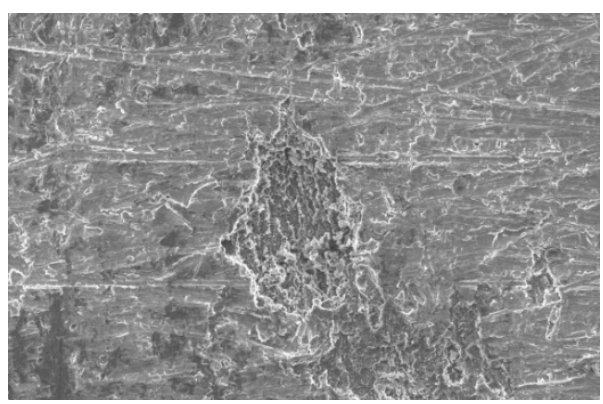

(b)

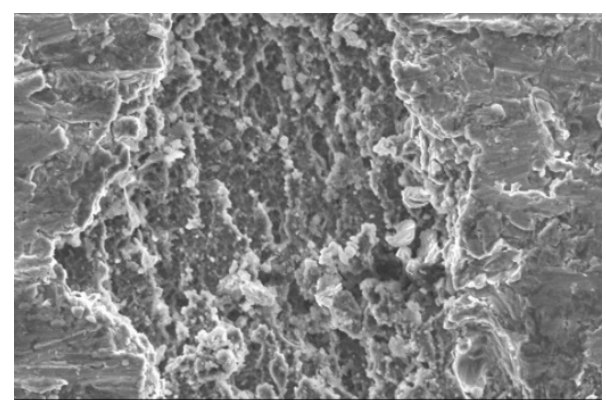

(c)

Fig. 7 SEM Image for coated sample of $0.018 \mathrm{~A} / \mathrm{mm}^{2}$ current density under magnification 1000X in (a) $0.5 \mathrm{M}$ (b) $1.0 \mathrm{M}$ and (c) $1.5 \mathrm{M} \mathrm{NaCl}$ solution

\section{Conclusion}

For metallic materials, the corrosion process is normally electrochemical. In this process, a chemical reaction occurs and electron transfers from one chemical species to another, as follows

$$
\begin{aligned}
& 2 \mathrm{NaCl}+2 \mathrm{H}_{2} \mathrm{O} \longrightarrow \mathrm{Cl}_{2}+\mathrm{H}_{2}+2 \mathrm{NaOH} \\
& \mathrm{Al}^{3+}+3 \mathrm{NaOH} \longrightarrow 2 \mathrm{Al}(\mathrm{NaOH})_{3}
\end{aligned}
$$

The compound $\mathrm{Al}(\mathrm{NaOH})_{3}$ is the compound found as the detected corrosion. The test shows that when in contact with the surface of aluminium alloy 6061 , the increase in current density during anodizing decreases the mass loss, hence corrosion rate. This work also identified that the rate of corrosion in aluminium alloy 6061 has an increasing trend towards the increment of $\mathrm{NaCl}$ solution concentration. Furthermore, by the decrement of solution $\mathrm{pH}$ value, the rate of corrosion increases.

Other factors that may contribute to the rate of corrosion is the electrode potential of material. By referring to the electrode potential, studies have shown that aluminium alloy 6061 is more active than sodium hydroxide $(\mathrm{NaOH})$ and more susceptible to oxidation. A more realistic and practical ranking however may be provided by the galvanic series. The galvanic series also show that aluminium alloy 6061 is more cathodic than sodium hydroxide, which further verifies the findings. The standard 
electrode potential and galvanic series reveal a high degree of correspondence between the relative positions of the materials.

\section{References}

[1] POLMEAR, I., STJOHN, D., NIE, J.F. and QIAN, M. Light Alloys: Metallurgy of the Light Metals. $5^{\text {th }}$ ed. Oxford: Butterworth-Heinemann, 2017. 544 p. ISBN 978-0-08-099431-4.

[2] GHALI, E. Corrosion Resistance of Aluminum and Magnesium Alloys: Understanding, Performance, and Testing. Hoboken: Wiley, 2010. 752 p. ISBN 978-0471-71576-4.

[3] SIVASANKARAN S. (ed.) Aluminium Alloys: Recent Trends in Processing, Characterization, Mechanical Behaviour and Applications. Norderstedt: Books on Demand. 2017. 324 p. ISBN 978-953-51-3698-9.

[4] Miller, W.S., ZHUANG, L., BOTTEMA, J., WITTEBROOD, A.J., SMET, P. de, HASZLER, A. and VIEREGGE, A. Recent Development in Aluminium Alloys for the Automotive Industry. Materials Science and Engineering, 2000, vol. 280, no. 1, p. 37-49. DOI 10.1016/S0921-5093(99)00653-X.

[5] RAMASWAMY, V., PAREEK, R., GIRI, A., ANUGULA, G., SRIVASTAVA, V. and ADHIKIRA, S. Corrosion Performance Evaluation of Aluminum Alloys for Automotive Applications. In Proceedings of the $16^{\text {th }}$ National Congress on Corrosion Control. Kolkata: NCCI, 2012, p. 23-25.

[6] LI, X., NIE, X., WANG, L. and NORTHWOOD, D. Corrosion Protection Properties of Anodic Oxide Coatings on an Al-Si Alloy. Surface and Coatings Technology, 2005, vol. 200, no. 5-6, p. 1994-2000. DOI 10.1016/j.surfcoat. 2005.08.019.

[7] ZHANG, K. and PARK, S.-S. Effects of Current Density on Anodizing Behavior, Micro-Structure, and Electrical Properties of $\mathrm{ZrO}_{2}$-coated Al Foils. Applied Surface Science, 2019, vol. 477, p. 44-49. DOI 10.1016/j.apsusc.2018.01.119.

[8] ASTM G46-94(2018). Standard Guide for Examination and Evaluation of Pitting Corrosion. West Conshohocken: ASTM International, 2018. DOI 10.1520/G0046-94R18.

[9] ASTM B209M-14. Standard Specification for Aluminum and Aluminum-Alloy Sheet and Plate (Metric). West Conshohocken: ASTM International, 1999. DOI 10.1520/B0209M-14.

[10] ASTM G 1-90(1999). Standard Practice for Preparing, Cleaning and Evaluating Corrosion Test Specimens. West Conshohocken: ASTM International, 1999. DOI 10.1520/G0001-90R99E01.

[11] CHUNG, I.C., CHUNG, C.K. and SU, Y.K. Effect of Current Density and Concentration on Microstructure and Corrosion Behaviour of 6061 Al Alloy in Sulphuric Acid. Surface and Coatings Technology, 2017, vol. 313, p. 299-306. DOI 10.1016/j.surfcoat.2017.01.114.

[12] ASHBY, M.F. and JONES, D.R.H. Engineering Materials 1: An Introduction to Properties, Application and Design. $4^{\text {th }}$ ed. Oxford: Butterworth-Heinemann, 2012. 496 p. ISBN 978-0-08-096665-6. 